\title{
A comparison of basal reflectivity and ice velocity in East Antarctica
}

\author{
R. W. Jacobel ${ }^{1}$, K. E. Lapo ${ }^{1}$, J. R. Stamp ${ }^{1}$, B. W. Youngblood ${ }^{1}$, B. C. Welch ${ }^{1}$, and J. L. Bamber ${ }^{2}$ \\ ${ }^{1}$ Department of Physics, St. Olaf College, Northfield, MN, 55057, USA \\ ${ }^{2}$ School of Geographical Sciences, University of Bristol, Bristol, BS8 1SS, UK
}

Received: 26 July 2010 - Published in The Cryosphere Discuss.: 11 August 2010

Revised: 7 October 2010 - Accepted: 8 October 2010 - Published: 18 October 2010

\begin{abstract}
Ground-based radio echo sounding data acquired along the $1700 \mathrm{~km}$ US-ITASE traverse have been used to determine ice attenuation and relative basal reflectivity across the major catchments funneling ice from East Antarctica to the Ross Ice Shelf. We find that basal reflectivity varies locally by up to $40 \mathrm{~dB}$ which we interpret as due to changes in the phase state at the bed. Some, though not all, areas of high local reflectivity are observed to have flat-lying bed reflections indicative of sub-glacial lakes. We compare basal reflectivity to ice balance velocity and find a general association of higher flow speeds with high radar reflection strength. This set of observations from two independent remotely sensed geophysical data sets extends the range of field observations to the interior of East Antarctica and confirms the importance of basal lubrication on modulating the ice dynamics of the largest ice sheet on the planet.
\end{abstract}

\section{Introduction}

The discovery of numerous lakes beneath the Antarctic Ice Sheets (e.g. Siegert et al., 2000) and the observation that in some cases lakes drain and refill on annual to sub-annual time scales (e.g. Smith et al., 2009; Carter et al., 2009; Fricker et al., 2007; Wingham et al., 2006) indicates that a pervasive sub-glacial hydrological network extends beneath large swathes of the ice in Antarctica. Basal melting, supporting till deformation of West Antarctic ice streams, is responsible for $\sim 90 \%$ or more of the velocity (Blankenship et al., 2001). In East Antarctica, where a pervasive, thick layer of deformable sediment is less likely, the role of subglacial

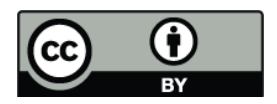

Correspondence to: R. W. Jacobel (jacobel@stolaf.edu) water on ice dynamics is less clear, less well documented and until recently generally limited to the role of water storage. For example, sub-glacial lakes at the head of Recovery Glacier in Coates Land have been linked with the onset of enhanced flow in this region (Bell et al., 2008) and other water reservoirs have been identified near the start of enhanced flow (Siegert and Bamber, 2000; Stearns et al., 2008). Mapping the distribution of subglacial water and elucidating the correspondence between its occurrence and ice flow speeds is thus of crucial importance for understanding the controls on ice dynamics across the whole of Antarctica.

\section{Radar data and analysis}

We have acquired $1700 \mathrm{~km}$ of ground-based radio echo sounding data along the 2006-2008 US-ITASE traverse from Taylor Dome to South Pole (Mayewski et al., 2003). In addition to providing ice thickness measurements, these data allow us to determine radar attenuation in the ice and calculate values of relative basal reflectivity. This route (Fig. 1) comprises a gate crossing the catchments of the major glaciers draining ice from East Antarctica into the Ross Sea providing us the opportunity to acquire continent-scale ground-based radar data. After correction for geometric and attenuation losses, the amplitude of basal radar returns is determined primarily by water content at the ice-bed interface where thawed conditions exert a major control on ice speed. Thus a primary goal of acquiring these data was to investigate the spatial distribution of thawed basal conditions and explore its relationship to ice dynamics.

The St. Olaf impulse radar (Welch and Jacobel, 2003) operated at $3 \mathrm{MHz}$ center frequency and recorded traces (each of 1000 stacks) at $3.5 \mathrm{~m}$ spacing along the traverse, providing a nearly continuous record of basal echoes for over

Published by Copernicus Publications on behalf of the European Geosciences Union. 


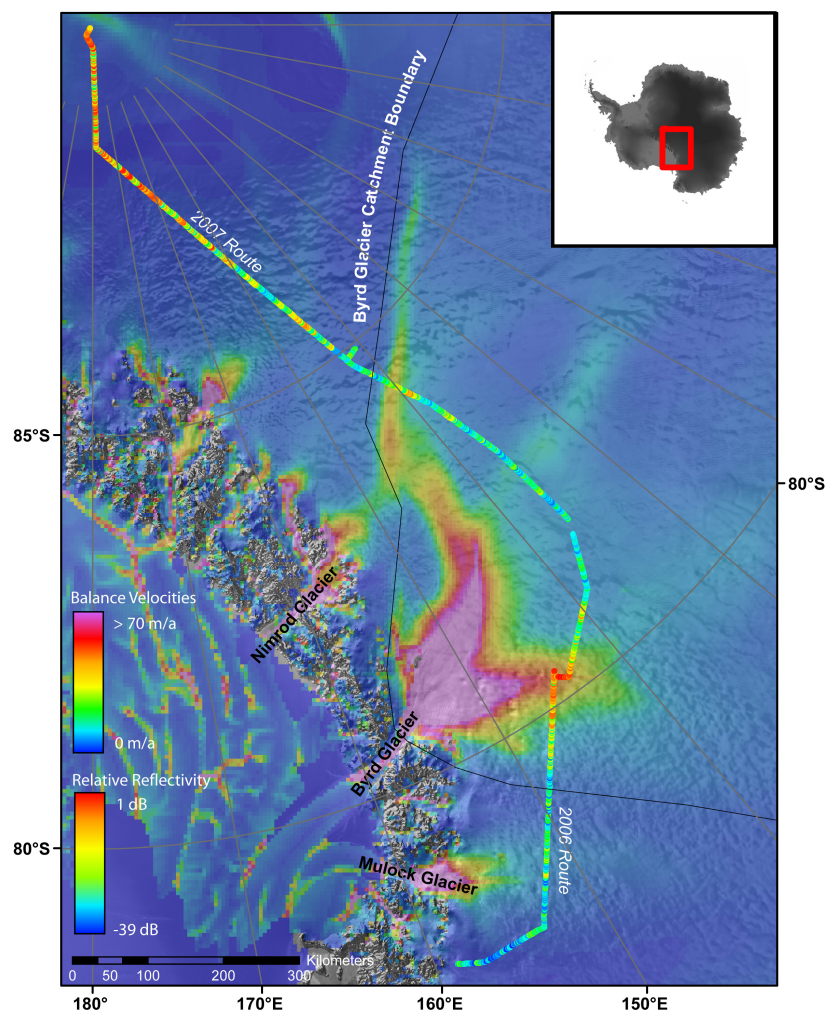

Fig. 1. Map showing the 2006-2008 US-ITASE route, Taylor Dome to South Pole. Color along the route indicates relative basal reflectivity in $\mathrm{dB}$. Also depicted in color are the balance velocities. The correspondence between areas of high basal reflectivity (wet bed) and ice speed is most notable in portions of the Byrd Glacier catchment.

$1700 \mathrm{~km}$. Ice internal echoes (isochronal layers) were also well-depicted for most of the traverse, occasionally to depths near $3 \mathrm{~km}$, and are discussed in more detail in Welch et al. (2009) and in work still in progress. In this study, a total of some 464000 bed echoes were analyzed to determine the relative reflectivity of the basal interface from Taylor Dome to South Pole. Recorded waveforms were first bandpassed to improve signal to noise and the data were subsequently migrated to remove the geometric effects of non-directional antennas. Power values were obtained by summing the squared amplitude under the bed echo wavelet (Gades et al., 2000).

\subsection{Modeling dielectric attenuation}

Assuming a constant (but uncalibrated) radar transmitted power, the power of electromagnetic energy returned from the basal interface is determined by three factors: the dielectric properties of the reflector (the basal reflectivity), losses due to geometric spreading, and losses due to dielectric attenuation within the ice, Eq. (1).

$P_{\mathrm{r}}=P_{\mathrm{t}} \frac{A}{4 \pi} \frac{1}{(2 h)^{2}} R \exp \left(-2 h / L_{\mathrm{a}}\right)$.

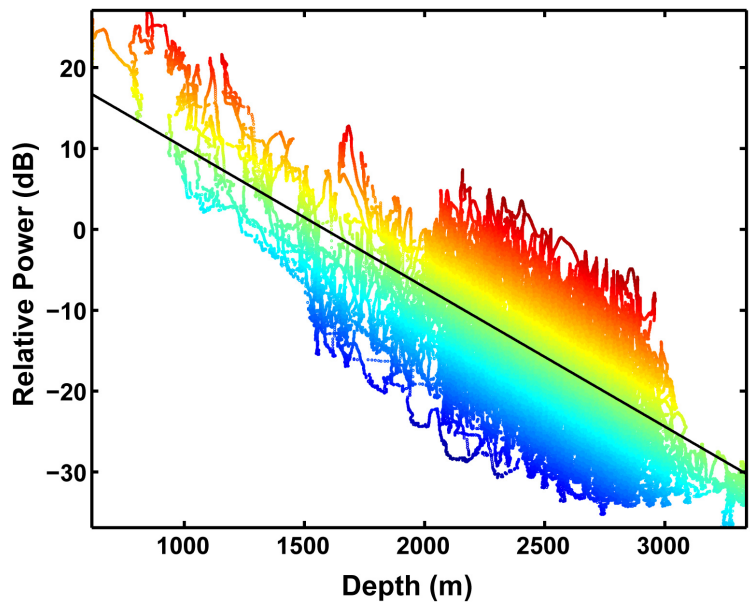

Fig. 2. Detected bed echo power $d B$ for the entire data set of 464000 points, normalized to power from a highly reflective subglacial lake. Linear least squares fit yields a slope of $8.6 \pm$ $0.1 \mathrm{~dB} / \mathrm{km}$, the average depth-averaged one-way dielectric attenuation. Color scale indicates relative basal reflectivity, the vertical distance of each point from the best fit line. For example, points above the fit line (warm colors) indicate areas of highly reflective (wet) bed.

Here $P_{\mathrm{t}}$ is the transmitted power, $A$ is the antenna gain function, $h$ is the one-way path length, $R$ is the reflectivity of the target interface (an internal layer or the bed) and $L_{\mathrm{a}}$ is the mean attenuation length due to dielectric loss. For near-normal incidence, where the transmitter/receiver antenna spacing is much less than the ice thickness, $h$ is effectively the ice thickness when considering bed echoes. $P_{\mathrm{r}}$ is subject to both inverse square losses from geometric spreading of the radar energy $\left(1 / 2 h^{2}\right)$ and exponential losses due to dielectric attenuation $\left(\exp \left(-2 h / L_{\mathrm{a}}\right)\right)$.

Taking the $\log _{10}$ of both sides of Eq. (1), the more commonly used one-way attenuation rate, $\left(N_{\mathrm{a}}\right)$ in $\mathrm{dB} \mathrm{km}^{-1}$ is related to $L_{\mathrm{a}}$ in meters by:

$N_{\mathrm{a}}=10^{3}\left(10 \log _{10} e\right) / L_{\mathrm{a}}$.

From Eq. (1), the geometric inversed-squared losses may be calculated simply with knowledge of the ice thickness. Dielectric attenuation is primarily a function of ice temperature but also depends on impurity content (e.g. MacGregor et al., 2007; Jacobel et al., 2009) and must be estimated. We have used four methods (discussed next) to model dielectric attenuation and have found them in good agreement.

Plotting all 464000 values of relative bed echo returned power (corrected for inverse square losses) versus depth gives a cluster of points with generally decreasing power at greater depths due to the dielectric attenuation (Fig. 2). Because we have no absolute measure of echo power, $\mathrm{dB}$ values are computed relative to a very strong and flat-lying reflector about $260 \mathrm{~km}$ from South Pole, very likely a subglacial lake. The least-squares fitted slope of this collection of points 
gives a measure of the mean dielectric attenuation length, which via Eq. (2) yields a depth-averaged one-way attenuation value of $8.6 \pm 0.1 \mathrm{~dB} / \mathrm{km}$. This method assumes that for a large statistical sample, all values of reflectivity are equally likely, independent of depth. Replotting the data with the average trend removed thus corrects for the dielectric attenuation and the value of power above or below the fitted line is a measure of the relative basal reflectivity for that point (Jacobel, et al., 2009). The histogram of these relative basal reflectivity values (Fig. 3) has a range of about $40 \mathrm{db}$ and is well fit by a double Gaussian model. A larger population of echoes with low reflectivity values (mean $-18.8 \mathrm{~dB}$, FWHM $14.1 \mathrm{~dB}$ ) is separated from a smaller population with higher reflectivity (mean $-11.8 \mathrm{~dB}$, FWHM $8.3 \mathrm{~dB}$ ) by $7 \mathrm{db}$ (difference of the means). While there is some overlap of echoes within one standard deviation between the two means, there is sufficient separation to clearly distinguish wet from dry basal conditions between the highest and lowest values.

\subsection{Variable attenuation models}

Because the temperature profile of the ice varies substantially from Taylor Dome to South Pole (Price et al., 2002; Waddington et al., personal communication, 2010) we explored two additional methods to model dielectric attenuation as a function of distance along the traverse, both relying on power received from englacial reflectors. The first method was based on the power returned from the strongest englacial reflectors. The second utilized the decrease in RMS power with depth of all internal echoes. For $35 \mathrm{~km}$ segments of the traverse (approximately 1000 traces), we computed a running average of the depth-corrected relative power returned from internal echoes and plotted this as a function of depth. In the first method, only the maximum values in this distribution (the brightest echoes) were then fit with a linear least-squares function. Assuming that the brightest internal reflectors have the same reflectivity and occur with equal probability at all depths, the slope of the fitted function is again a measure of the depth-averaged dielectric attenuation for that segment (Matsuoka et al., 2010). These plots generally have a welldefined upper cutoff that shows a strong linear dependence with depth, justifying the assumption. Values obtained in this way show local variations of up to $50 \%$ from a mean of $9.6 \mathrm{~dB} / \mathrm{km}$ (one-way), with an overall trend of decreasing attenuation at the higher elevations approaching South Pole, presumably because of colder temperatures of the ice. The best linear fit to these values gives one-way attenuations ranging from approximately $11 \mathrm{~dB} / \mathrm{km}$ near Taylor Dome to $7 \mathrm{~dB} / \mathrm{km}$ at South Pole. Variations about this trend were not correlated with ice thickness, layer geometry or basal topography. These values of attenuation are about 50\% lower than those we have measured in West Antarctica (Jacobel et al., 2009), again likely because of warmer ice temperatures there. We used the values from this linear trend in our computations of relative basal reflectivity described below.

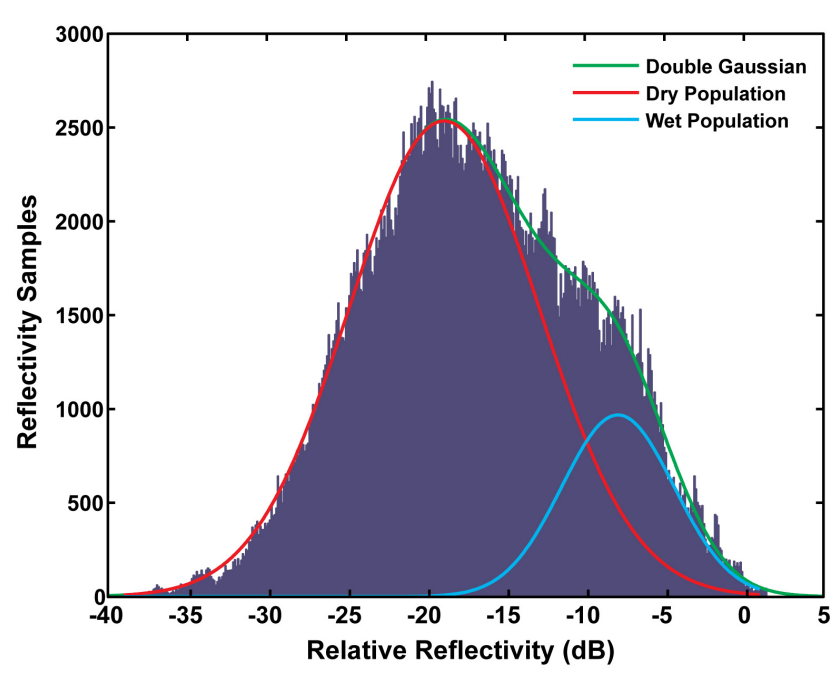

Fig. 3. Histogram of relative bed echo reflectivities in $\mathrm{dB}$. The distribution of 464000 points has a mean of $-15.9 \mathrm{~dB}$ and FWHM of $19 \mathrm{~dB}$. It is well fit by a double Gaussian function with a population centered at $-18.8 \mathrm{~dB}$, FWHM $14.1 \mathrm{~dB}$ and a more reflective population centered at $-11.8 \mathrm{~dB}$, FWHM $8.3 \mathrm{~dB}$. We identify echoes to the left as indicative of dry basal condition and those to the right as wet. Reflectivity values are scaled to a highly reflective subglacial lake that plots at $0 \mathrm{~dB}$ in this figure.

A similar model for the RMS power returned from all internal reflectors within each $35 \mathrm{~km}$ window gave a second set of attenuation estimates as a function of distance along the traverse. These values match closely those from the brightest echoes, giving confidence that power returned from internal layers is very similar whether one considers all returns or only the brightest.

A fourth method for calculating attenuation applied in the shallower ice near Taylor Dome used the standard geophysical technique of measuring the amplitude of secondary bed echoes (two round trips through the ice with an internal reflection at the surface) (e.g., MacGregor et al., 2010; Peters et al., 2008) and gave similar results.

\section{Basal reflectivity}

Colors along the traverse route in Fig. 1 indicate the computed relative basal reflectivity in a $\mathrm{dB}$ scale using the modeled trend of values for dielectric attenuation obtained from the brightest internal echoes model. They have been smoothed with a $500 \mathrm{~m}$ running average to remove the effects of small-scale roughness and noise. The calculated values shown in this map vary by up to $40 \mathrm{db}$ and are not sensitive to the method used for removing dielectric attenuation. Results are similar whether a single value for attenuation is used or the along-traverse values computed by either of the models using the power from internal layers. As an overall trend, basal reflectivity generally increases toward 
South Pole where ice near the pressure melting point has been reported at the bed (Price et al., 2002). Other areas of high basal reflectivity correspond with topographic features such as abrupt bedrock rises and subglacial lakes (Welch et al., 2009), some of which have been suggested by elevation changes seen in satellite imagery (Smith et al., 2009). But it is noteworthy that not all candidate satellite-inferred lake sites show high basal reflectivity (Welch et al., 2009). The area of highest bed reflectivity (discussed below) is found in the northern portion of the Byrd Basin where the traverse crosses a region of slightly elevated bedrock.

Basal roughness can impact the measurement of radar power received from the bed because of scattering and thus potentially confound the calculation of reflectivity. With a wavelength of $\sim 50 \mathrm{~m}$ in ice, we would not expect our radar to be sensitive to roughness features on scales less than one to two hundred meters at typical depths (roughly the first Fresnel Zone). In principal, our along-track resolution is improved somewhat by our $3.5 \mathrm{~m}$ trace separation which enables us to use migration techniques (similar to SAR processing) to collapse diffraction hyperbolas and capture the energy from roughness features with slopes less than about 45 degrees. Also, in these plots we have smoothed the reflectivity data with a running average of $500 \mathrm{~m}$ so that variations should depict changes in bed dielectric properties as opposed to scattering losses.

To show more clearly the relationship between bed topography and reflectivity we have plotted data from the northern portion of the Byrd Basin (Fig. 4). The highest values of basal reflectivity occur from $\mathrm{km} 400$ to 500 where the traverse route turns briefly along flow from the Byrd Glacier (Figs. 1 and 4 at Site 06-4). Reflectivity remains consistently high across most of this section ( $\mathrm{km} 350-500)$ despite roughness features of several hundred meters relief at the scale of several kilometers. Areas both before and following this section with essentially the same bed roughness show much lower reflectivity by $20 \mathrm{~dB}$ or more. From this we conclude that our interpretation of thawed basal conditions is not an artifact related to scattering losses from bed roughness. We turn next to investigate the correspondence of basal reflectivity with ice speed.

\section{Ice velocities}

Surface ice velocities were derived from a combination of tandem phase ERS-1 interferometric SAR (InSAR) and longer repeat ERS-1 (35 day) and RADARSAT (24 day) InSAR and speckle tracking data sets produced by several different groups at the University of Washington, Jet Propulsion Laboratory and Ohio State University (Edwards, 2009). The different data sets were combined, where overlapping, using a weighted average based on the formal error estimates for each velocity estimate (Edwards, 2009). Balance velocities covering the entire region of the traverse were estimated us-

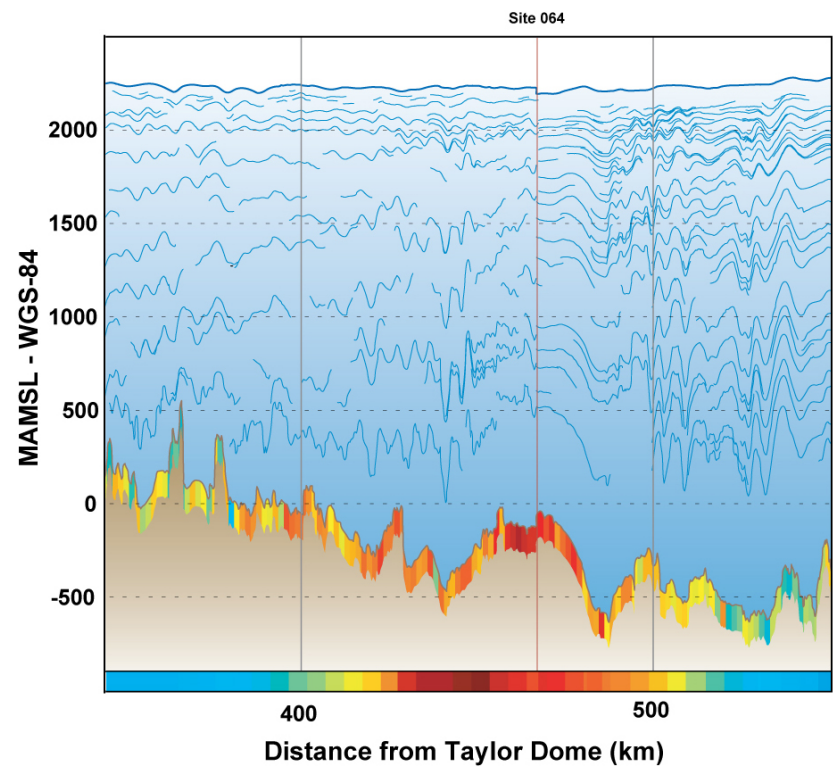

Fig. 4. Basal reflectivity, topography and prominent internal layers from a portion of the traverse in the northern Byrd Basin corresponding to higher velocities. Balance velocities are also shown across the bottom of the figure for comparison with reflectivity. Velocity colors are scaled to the range of balance velocities, approximately $0-70 \mathrm{~m} / \mathrm{a}$. Areas of high basal reflectivity (warm colors) are independent of bed roughness and ice thickness, and correspond closely with velocity. Basal reflectivity color scale is in $\mathrm{dB}$, the same scale used in Figs. 1 and 2. The apparent discontinuity at site 06-4 corresponds to a short segment oriented perpendicular the rest of the traverse to circumvent a region of crevasses.

ing a standard finite difference scheme (Budd and Warner, 1996) combined with a new digital elevation model and accumulation estimates for the ice sheet (Bamber et al., 2009).

Comparisons between the basal reflectivity and ice speeds were made using both the InSAR and balance velocity data sets. However, coverage of the InSAR velocities unfortunately is limited and also discontinuities occur at the seams where satellite coverage ends, making it difficult to splice together InSAR and balance velocity data sets in a single comparison. For that reason, only comparisons with balance velocities are described here (colors in Fig. 1). While they are less accurate than the InSAR velocities, they have been shown to capture well the spatial pattern of fast flow (Bamber et al., 2009). The correspondence between measured InSAR surface velocities and relative basal reflectivity is most striking in the northern part of the Byrd basin near $80^{\circ} \mathrm{S}$ latitude, $145^{\circ} \mathrm{E}$ longitude where the areas of highest velocity align with high bed reflectivity. The color bar across the bottom of Fig. 4 shows the balance velocities plotted for comparison with basal reflectivity and the strong correlation is apparent. On the other side of the Byrd catchment to the south, the bed is also more reflective where increasing ice speeds near the southern margin $\left(85^{\circ} \mathrm{S}\right)$ begin to form the southern-most 


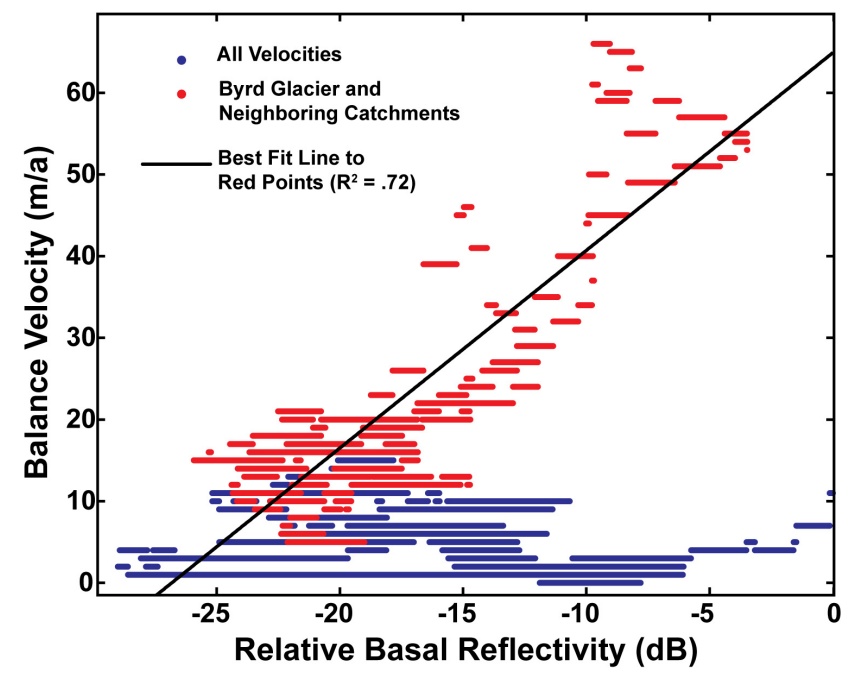

Fig. 5. Scatter plot showing the correspondence between basal reflectivity and balance velocities. Velocities are gridded to $5 \mathrm{~km}$. Reflectivity has been smoothed to show features with a spatial scale of $5 \mathrm{~km}$ or greater. Points in red are limited to portions of the traverse in or around the Byrd Glacier Catchment (organized flow) shown in Fig. 1. Blue points are balance velocities compared to reflectivity for the entire traverse. The black line is a least squares regression to only the organized flow (points in red) with an $R^{2}=0.72$.

tributary. Less apparent, but following the same trend, is the central tributary where bed reflectivity values are also higher. South of the Byrd catchment, the traverse is too far inland to be sensitive to organized flow and values of basal reflectivity are generally higher everywhere, corresponding to conditions near thawing.

\section{Discussion and conclusions}

To explore more quantitatively the correspondence between surface velocity and basal reflectivity for the entire traverse we have plotted the balance velocities versus basal relative reflectivity (Fig. 5). Points along the traverse north of $85^{\circ}$ are plotted in red while points to the south are blue. This is an approximate division of where ice flow is organized into the major drainage catchments to the north (e.g. Byrd, Nimrod) and less organized ice sheet flow in the interior of the ice sheet to the south. The fitted line is a linear least squares regression to the points north of $85^{\circ}$ only (red) showing an $R^{2}$ value of 0.72 . Including points from the southern portion of the traverse in the fit lowers the $R^{2}$ value to below 0.5 because, as noted above, much of the bed there has high reflectivity while velocities are low in this part of the ice sheet where flow is not organized. The distribution of these points suggests that above a threshold velocity of approximately $10 \mathrm{~m} / \mathrm{a}$, velocities are strongly correlated with basal reflectivity, whereas areas with lower velocity can occur across a range of reflectivity values.
The correspondence between higher surface velocities and stronger basal reflectivity is not surprising given that basal lubrication provides the major control on ice motion in areas such as the ice streams in West Antarctica. In Greenland, the largest "ice stream" feature, extending some $650 \mathrm{~km}$ into the ice sheet interior has been linked to a geothermal hotspot resulting in large subglacial water production (Fahnestock et al., 2001). Studies on fast flow features in East Antarctica are, however, more limited both in number and detail. As a consequence, the role of basal hydrology on ice dynamics in East Antarctica is less clear. Where investigated, fast flow features in East Antarctica appear to be controlled to some extent by bedrock topography (e.g. Rippin et al., 2003), lying in troughs. Deeper, thicker ice is warmer at depth, resulting in a lower viscosity and a higher driving stress. Deformational velocity is proportional to the fourth power of ice thickness and it is possible, therefore, that fast flow features in East Antarctica do not require an additional mechanism to account for their existence. For the deepest, thickest tributary feeding Slessor Glacier, however, basal sliding was found to be important to the ice motion (Rippin et al., 2003). This appears also to be the case here. The correspondence between high reflectance and areas of fast flow strongly suggests that basal lubrication is contributing to the motion. We note, however, that toward the South Pole, areas of wet bed are identified, which do not correspond with regions of enhanced flow. This is consistent with other model and observational results (e.g., Bell, 2008; Bell et al., 2007), confirming that basal lubrication is a necessary but not sufficient condition for enhanced flow in this sector of East Antarctica.

The present study shows that areas of thawed bed in East Antarctica are not limited to isolated lakes and that they are widespread. The strong correspondence between regions of thawed bed and ice speed demonstrated here shows that basal hydrology plays a critical role in the dynamics of the entire continent.

Acknowledgements. We are grateful for the assistance in the field provided by our colleagues on the US-ITASE traverse 2006-2008 and the support from members of Raytheon Polar Services. We thank several members of our research group at St. Olaf College who made valuable contributions to this work by picking the bed and internal layer horizons, particularly Jessica Olson and Jacki Werner. Very helpful comments were provided by Ed King and an anonymous reviewer. Finally we acknowledge the National Science Foundation for their funding of this project with award 0440304 to St. Olaf College.

Edited by: I. M. Howat

\section{References}

Bamber, J. L., Gomez-Dans, J. L., and Griggs, J. A.: A new 1 km digital elevation model of the Antarctic derived from combined satellite radar and laser data, Part I: Data and methods, The Cryosphere, 3, 101-111, doi:10.5194/tc-3-101-2009, 2009. 
Bell, R. E.: The role of subglacial water in ice-sheet mass balance, Nat. Geosci., 1, 297-304, doi:10.1038/ngeo186, 2008.

Bell, R. E., Studinger, M., Shuman, C. A., Fahnestock, M. A., and Joughin, I.: Large subglacial lakes in East Antarctica at the onset of fast-flowing ice streams, Nature, 445, 904-907, 7130, doi:10.1038/nature05554, 2007.

Blankenship, D. D., Morse, D. L., Finn, C. A., Bell, R. E., Peters, M. E., Kempf, S. E., Hodge, S. M., Studinger, M., Behrendt. J. C., and Brozena, J. M.: Geological controls on the initiation of rapid basal motion for the West Antarctic Ice Streams: a geophysical perspective including new airborne radar sounding and laser altimetry results, Ant. Res. Ser., 77, 105-121, 2001.

Budd, W. F. and Warner, R. C.: A computer scheme for rapid calculations of balance-flux distributions, Ann. Glaciol., 23, 21-27, 1996.

Carter, S. P., Blankenship, E. E., Young, D. A., Peters, M. E., Holt, W., and Siegert, M.: Dynamic distributed drainage implied by the flow evolution of the 1996-1998 Adventure Trench subglacial lake discharge, Earth Planet. Sc. Lett., 283, 24-37, doi:10.1016/j.epsl.2009.03.019, 2009.

Edwards, L.: Antarctic ice velocities from satellite observations: generation, validation and application, Ph.D. thesis, University of Bristol, 267 pp., 2009.

Fahnestock, M., Abdalati, W., Joughin, I., Brozena, J., and Gogineni, P.: High geothermal heat row, basal melt, and the origin of rapid ice how in central Greenland, Science, 294, 2338-2342, 5550, doi:10.1126/science.1065370, 2001.

Fricker, H. A., Scambos, T., Bindschadler, R., and Padman, L.: An active subglacial water system in West Antarctica mapped from space, Science, 315, 1544-1548, 5818, doi:10.1126/science.1136897, 2007.

Gades, A. M., Raymond, C. F., Conway, H. B., and Jacobel, R. W.: Bed properties of Siple Dome and adjacent ice streams, West Antarctica, inferred from radio echo-sounding measurements, J. Glaciol., 46(152), 88-94, 2000.

Jacobel, R. W., Welch, B. C., Osterhouse, D., Pettersson, R., and MacGregor, J. A.: Spatial Variation of Radar-Derived Basal Conditions on Kamb Ice Stream, Ann. Glaciol., 50(51), 10-16, 2009.

MacGregor, J. A., Anandakrishnan, S., Winebrenner, D. P., Catania, G. A., and Joughin, I.: Inferring englacial radar attenuation and the onset of basal accretion from multiple bed echoes over the Ross Ice Shelf, J. Geophys. Res., submitted, 2010.

MacGregor, J. A., Winebrenner, D. P., Conway, H., Matsuoka, K., Mayewski, P. A., and Clow, G. D.: Modeling englacial radar attenuation at Siple Dome, West Antarctica, using ice chemistry and temperature data, J. Geophys. Res., 112, F03008, doi:10.1029/2006JF000717, 2007.
Matsuoka, K., Morse, D., and Raymond, C. F.: Estimating englacial radar attenuation using depth profiles of the returned power, Central West Antarctica, J. Geophys. Res., 115, F02012, doi:10.1029/2009JF001496, 2010.

Mayewski, P. A.: Antarctic oversnow traverse-based Southern Hemisphere climate reconstruction, EOS T. Am. Geophys. Un., 84(22), doi:10.1029/2003EO220002, 2003.

Peters, L. E., Anandakrishnan, S., Holland, C. W., Horgan, H. J., Blankenship, D. D., and Voigt, D. E.: Seismic detection of a subglacial lake near the South Pole, Antarctica, Geophys. Res. Lett., 35, L23501, doi:10.1029/2008GL035704, 2008.

Price, B., Nagornov, O. V., Bay, R., Chirkin, D., He, Y., Miocinovic, P., Richards, A., Woschnagg, K., Koci, B., and Zagorodnov, V.: Temperature profile for glacial ice at the South Pole: Implications for life in a nearby subglacial lake, P. Natl. Acad. Sci. USA, 99(12), 7844-7847, doi:10.1073pnas.082238999, 2002.

Rippin, D. M., Bamber, J. L., Siegert, M. J., Vaughan, D. G., and Corr, H. F. J.: The role of ice thickness and bed properties on the dynamics of the enhanced flow tributaries of Bailey Ice Stream and Slessor Glacier, East Antarctica, Ann. Glaciol., 39, 366-372, 2004.

Rippin, D. M., Bamber, J. L., Siegert, M. J., Vaughan, D. G., and Corr, H. F. J.: Basal topography and ice flow in the Bailey/Slessor region of East Antarctica, J. Geophys. Res.-Earth, 108(F1), 6008-6019, doi:10.1029/2003JF000039, 2003.

Siegert, M. J.: Antarctic subglacial lakes, Earth-Sci. Rev., 50(1-2), 29-50, 2000.

Siegert, M. J. and Bamber, J. L.: Subglacial water at the heads of Antarctic ice-stream tributaries, J. Glaciol., 46(155), 702-703, 2000.

Smith, B. E., Fricker, H. A., Joughin, I. R., and Tulaczyk, S.: An inventory of active subglacial lakes in Antarctica detected by ICESat (2003-2008), J. Glaciol., 55(192), 573-594, 2009.

Stearns, L. A., Smith, B. E., and Hamilton, G. S.: Increased flow speed on a large East Antarctic outlet glacier caused by subglacial floods, Nat. Geosci., 1, 827-831, doi:10.1038/ngeo356, 2008.

Welch, B. C., Jacobel, R. W., and Arcone, S.: First results from radar profiles collected along the US-ITASE traverse from Taylor Dome to South Pole (2006-2008), Ann. Glaciol., 50(51), 35-41, 2009.

Welch, B. C. and Jacobel, R. W.: Analysis of deep-penetrating radar surveys of West Antarctica, US-ITASE 2001, Geophys. Res. Lett., 30(8), 1444, doi:10:1029/2003GL017210, 2003.

Wingham, D. J., Siegert, M. J., Shepard, A., and Muir, A. S.: Rapid discharge connects Antarctic subglacial lakes, Nature, 440, 1033-1036, doi:10.1038/nature04660, 2006. 